\title{
Research on Factors and Deployment Strategy of Grid Wildfire Disaster in Hunan Province of China
}

\author{
Yashan Zhong ${ }^{1, a^{*}}$ and Dongxiao Niu ${ }^{1, b}$ \\ ${ }^{1}$ School of Economics and Management, North China Electric Power University,Beijing, China \\ azhongyashan132@163.com, ${ }^{\mathrm{b}}$ niudx@126.com
}

Keywords: Grid; Wildfire disaster; Factors; Deployment strategy

\begin{abstract}
Most long-distance inter-regional power transmission grid lines are in unattended forest zone. In recent years, China's forest coverage has improved a lot which provide a lot of combustible material for the outbreak of the wildfire. Under the influence of global warming and other climatic anomalies factors, it leads to fire weather appears with increasing frequency which high temperature, low humidity, persistent drought and wind speed. With the electrification standards of production and living becoming higher and higher, the construction scale of the power grid is increasing. There are more and more regional transmission line trip and blackouts accidents caused by wildfire disasters. This paper analyzed the evolution mechanism of grid wildfire disaster. From three factors of geographical and climatic factors, combustible material factors and ignition sources factors, this paper qualitative and quantitative analyzed the Grid wildfire disaster impact factors, and proposed some wildfire disaster deployment strategy before the disaster, during the disaster and after the disaster. It helps prevent and reasonable response the grid wildfire disaster, and provide reasonable reference for grid security and operation and maintenance.
\end{abstract}

\section{Introduction}

Most long-distance inter-regional power transmission grid lines are in unattended forest zone. In recent years, China's forest coverage has improved a lot which provide a lot of combustible material for the outbreak of the wildfire. Under the influence of global warming and other climatic anomalies factors, it leads to fire weather appears with increasing frequency which high temperature, low humidity, persistent drought and wind speed. Global annual number of fires broke out is on the rise. Fires make transmission line tripped and impact the stable operation of power grid even cause blackouts. It reduced the reliability of power supply. Inter-regional power transmission line would inevitably have to cross a dense forest area, so it appear more and more line trip and blackouts accidents [1].

It is in favor of grid decisions and avoiding serious losses that to analyzed the wildfire disaster affecting the safe operation effectively [2,3]. This paper analyzed the evolution mechanism of grid wildfire disaster, qualitative and quantitative analyzed the Grid wildfire disaster impact factors, and proposed some wildfire disaster deployment strategy before the disaster. It helps prevent and reasonable response the grid wildfire disaster, and provide reasonable reference for grid security and operation and maintenance. This provides guidance for decision-making power disaster

\section{Fire Disaster Evolution Mechanisms}

In recent years, line trip and blackout accidents caused by wildfire increased in nationwide. It is seriously affected the normal production and life, resulting in greater social and economic losses.

The electrical outer insulating of transmission line is damaged by wildfire which caused discharge and trip, and most of it failed reclosing. The reason caused line trip is ground discharge and insulator flashover.

Barometric pressure, air temperature and humidity are the three main factors of external insulation discharge of electrical transmission line [4]. Changes in barometric pressure are mainly dependent on 
elevation changes. Pressure is essentially linearly with increasing altitude decreases. As the pressure reduces, the breakdown voltage of the air gap is reduced; Air temperature is related to altitude and latitude. But when there is wildfire in the bottom of transmission line, air temperature near the transmission line can be greatly increased in a short time. When fires burn, the flame temperature can reach 1000-1177 ${ }^{\circ} \mathrm{C}$. As air temperature increases the breakdown voltage of the air gap is reduced; there are many factors to humidity. Generally speaking, as the relative humidity drops, the breakdown voltage of the air gap is reduced.

When the fire occurred, it accompanied by a lot of smoke $[5,6]$. The smoke spread into the air which will reduce the dielectric constant of air; Smoke rising with the thermals, and combine with the free electrons in air which promote the development of electron avalanche between grounding body and wire. There are a few of tar in the fire smoke which is easy to glue insulator along with the diffusion of thermal motion. It will cause insulator flashover voltage reduced. If the fire is next to the tower, it will produce a lot of smoke around the insulator. Insulator flashover will occur directly and cause tripping accidents.

Tripping accidents caused by wildfires general failed in reclosing. After transmission line fires because tripping, automatic reclosing device will switch on in a very short period of time, It will produce a over-voltage operation higher than normal operating voltage. However, Dielectric strength of air medium has no time to recover because Fires are still burning. So the air gap will be breakdown again. Reclosing will continue to fail.

\section{Grid Wildfire Disaster Impact Factors Analysis}

There are a variety of factors of grid wildfire. Most of them are summary to three categories, geographical and climatic factors, combustible material factors and ignition sources factors [7].

Geographical and Climatic Factors. For example of Hunan province, Hunan is located in the southeast of China and the central, northern of it is flat. So Hunan formed a basin with opening north. Every February to April, the temperature rose, Hunan is in the southern part of warm low-pressure center where leading wind direction is southeasterly winds. In some sunny day, when warm air move to the inland from the coast, it will uplift and its temperature continues to drop. So the water vapor content of the air is gradually reaching saturation. As the temperature continues to fall, part of the steam become fog, rain and cloud. When the airflow comes to the Hunan Province over the top of the hill of these mountains, the temperature is gradually increased [8]. And the foehn wind is formed. If the ground is impacted for a few days by the foehn, the temperatures will get to rise and the relative humidity will drop. Therefore, the sticks and dry leaves on the ground and grasses will become very dry which provide favorable conditions for the outbreak of the wildfire.

Combustible Material Factors. Combustibles on the ground seldom absorb moisture due to the long-term drought, and high temperature, low relative humidity weather make strong evaporation which accelerate the loss of water in fuel. So the combustible can easily burn up by the sparks. On the one hand, wind speed up the evaporation of water, on the other hand, it can make to promote the spread of fire. Therefore firefighting and rescue work become very difficult [9].

Ignition Sources Factors. According to statistical results, it showed that more than 99 percent of the fire source of triggered fires in Hunan Province is artificial sources of ignition. The fire source of spring are productive use of fire of farmer plowing when burning manure and firecrackers when the Qingming Festival.

\section{Grid Wildfire Disaster Deployment Strategy}

Preventive Measures before the Wildfire Disaster. There are four preventive measures before the wildfire disaster, strict control of the fire and strengthen line inspection, cleanup transmission line channel and set up buffer zone, enhance the safety management level, and increase the scientific and technological of fire prevention applications. 
Strict Control of the Fire and Strengthen Line Inspection. According to statistical results, it showed that more than 99 percent of the fire source of triggered fires, so the best strategy is to prevent fires source. Strict control must be taken to prevent fires caused by human sources of ignition. And at special times (e.g. before and after Qingming festival) take a long-term extended stay in the key fire area to prevent fire [10].

Clean up Transmission Line Channel and set up Buffer Zone. Tease out the combustible under the transmission lines, such as the tree barrier, grass, rape, straw, cemeteries, etc. Strengthen the combustible hidden investigation surrounding the towers and transmission lines. And then register the fire zone in details. Clean the straw and flammable materials stacked under the line, and set up and broaden the buffer zone at Fire-prone area.

Enhance the Safety Management Level [11]. Establish an effective emergency response organization system, a complete emergency management system and standardize emergency security system. Standardize the information reporting system and the fire information should be submitted timely. Set up rescue teams equipped with fire extinguishers and gas masks, and other professional equipment; to carry out important transmission channel anti-fire assessment and develop targeted anti-fire control measures and response mechanisms. Meanwhile, the fire prevention emergency response plans should be timely revised and improved with fire accident characteristics. The various rules should be integrity and the emergency supplies should be prepared and ready to respond to the fire emergency.

Increase the Scientific and Technological of Fire Prevention Applications. Establish an anti-fire intelligent monitoring and warning system with high-tech tools and satellite monitoring means, with the satellite monitoring of forest fires instead of doing Mountaineer. So it can find fire hazards timely and locate a trouble accurately. What's more, it can forecast the spread of fire and Provide important support for the firefighting Decision.

Control Measures during the Wildfire Disaster. There are three Control measures during the wildfire disaster, enhance information coalition, rapid notification, and rapid disposal.

Enhance Information Coalition. Strengthen close ties with the forest fire department, to establish a joint fire normal mechanism and achieve the fire information sharing timely. After receiving the fire information near transmission line, the people should report to the dispatcher and superiors promptly. Dispatcher should adjust the line operation mode timely according to the fire development, to avoid significant losses.

Rapid Notification. Since the fire developed rapidly, when the line trip threat happened caused by the fire accident, the municipal power company should report the provincial power emergency fire information office timely.

Rapid Disposal. After identifying the basic situation of fire disaster, the provincial power company should organize fire disaster emergency leading group quickly. Emergency leading group should hold an emergency meeting and initiate anti-fire emergency plan immediately. On the one hand, according to fire hazard level, the group has the right to ask for assistance from the government, the forestry sector and forest fire department. On the other hand, dispatching sector should initiate emergency plan based on outage may cause by the fires level. Minimize the impact of fire disasters and recover normal supply of electricity.

Disposal Measures after the Wildfire Disaster. There are three disposal measures after the wildfire disaster, restore the power lines, restore the power supply, and accident Investigation.

Restore the Power Lines. When power facilities are damaged in a large area, the working group should quickly dispatch rescue teams and supplies to the scene to rescue as soon as possible. In the process of electric power accident rescue, the group could request local government departments and relevant institutions to provide transportation, communication, medical, supplies, personnel and other aspects of security and support. Repair teams should carry out repair work immediately. At the same time, the group should ensure restore important equipment first.

Restore the Power Supply. After widespread power outages, the power supply should be restored as soon as possible. Safe, fast and efficient power restoration is essential to reduce power loss, 
maintain social stability and restore normal order. In the power recovery process, the auxiliary power of large-scale power should be restored. Coordinate the recovery among grid, power plants and users. And make sure the security and stability of grid. What's more, according to the plan, restore electricity supplies of key areas, major cities and vital loads step by step.

Accident Investigation. After the fire disaster, it should set up an accident investigation team to invest the reasons for this fire disaster, processes, loss, recovery and accident responsibilities. The accident investigation team should propose preventive measures and treatment advice accident liability.

\section{Conclusion}

With the electrification standards of production and living becoming higher and higher, the construction scale of the power grid is increasing. There are more and more regional transmission line trip and blackouts accidents caused by wildfire disasters.

This paper analyzed the evolution mechanism of grid wildfire disaster. From three factors of geographical and climatic factors, combustible material factors and ignition sources factors, and then, this paper qualitative and quantitative analyzed the Grid wildfire disaster impact factors, and proposed some wildfire disaster deployment strategy before the disaster, during the disaster and after the disaster. It helps prevent and reasonable response the grid wildfire disaster, and provide reasonable reference for grid security and operation and maintenance.

\section{References}

[1] D.X. Niu, Respond to disasters - Power Crisis Management, Beijing, 2010

[2] J.J. Song, C.X. Guo, J.J. Zhang, etc, Overhead transmission line outage probability model under fire conditions. Grid Technologies, 2013, 37 (1): 100-105.

[3] Y. Zhang, G.T.Yang, L. Yu, BP neural network of transmission lines based on identifying fire hazards points, Technological Innovation and Application, 2014 (23): 46-47.

[4] Y.X. He, J. Zhu, T. Luo, etc, Urban grid planning Assessment of Natural Disasters. Electro technical Society, 2011 (12): 205-210.

[5] Z.G. Wang, N. Li, M.M. Zhang, Fire impact on the power grid and countermeasures in Hunan, Hunan Electric Power, 2012, 32 (1): 33-35.

[6] L.P. Ye, X.Y. Chen, Z.L. He, etc, Fire warning technology application status of the power transmission line, Protection and Control System, 2014 (6): 145-153.

[7] X. Hu, J.Z. Lu, X.J. Zeng, Transmission lines and other fire Tripping Analysis and Its Control Measures, Power Science and Technology, 2010, 25 (2): 73-78.

[8] Z.L. Wang, X.F. Zhao, G.L. Wu, Design and implementation of electric micro-meteorological disaster monitoring and early warning systems, Power and Energy, 2014 (6): 712-716.

[9] L.H. Fang, X.F. Xiong, F. Song, etc, Risk control decisions based on the system associated with the meteorological grid fault causal analysis, Power Protection and Control System, 2014 (17): 113-119.

[10] H. Fang, F. Yang, Z.H. Wen, Transmission line operation safety factors and measures of prevention, Chinese High-tech Enterprises, 2015 (31): 137-138.

[11] Y.S. Men, C.Y. Zhu, Z.Yu, etc, Network vulnerability assessment of critical infrastructure to natural disasters, Disaster, 2014 (4): 16-19. 